\title{
Determination of Atrazine and Simazine in Environmental Water Samples by Dispersive Liquid-Liquid Microextraction with High Performance Liquid Chromatography
}

\author{
Qingxiang Zhou, ${ }^{* \dagger}$ Long PANG, ${ }^{*}$ Guohong XIE, ${ }^{* *}$ Junping XIAO, ${ }^{* * *}$ and Huahua BAI* \\ *School of Chemistry and Environmental Sciences, Henan Normal University, Henan Key Laboratory for \\ Environmental Pollution Control, Key Laboratory for Yellow River and Huaihe River Water Environment \\ and Pollution Control, Ministry of Education, Xinxiang 453007, China \\ **College of Resources and Environment, Henan Institute of Science and Technology, \\ Xinxiang 453003, China \\ ***Department of Chemistry, University of Science and Technology Beijing, Beijing 100083, China
}

\begin{abstract}
This paper describes a new method for the rapid and sensitive analysis of atrazine and simazine based on the dispersive liquid-liquid microextraction with carbon tetrachloride and methanol as the extraction solvent and disperser solvent. Under the optimal conditions, there are excellent linear relationships between the peak area and the concentration in the range of $0.5-50 \mu \mathrm{g} \mathrm{L}^{-1}$ for atrazine and $0.1-50 \mu \mathrm{g} \mathrm{L}-1$ for simazine. The limits of detection were 0.1 and $0.04 \mu \mathrm{g} \mathrm{L}^{-1}$ for atrazine and simazine, respectively. The proposed method was also applied to the analysis of real water samples, and excellent results were achieved with spiked recoveries in the range of $60.7-91.4 \%$. All these results demonstrate that the proposed method would be widely used in many fields in the future.
\end{abstract}

(Received January 29, 2008; Accepted May 1, 2008; Published January 10, 2009)

\section{Introduction}

Nowadays, a great deal of pesticides are widely used in agriculture, and their heavy use has resulted in the environmental pollution. Moreover, their persistent presence had been a serious problem, especially in surface and ground water systems. Triazine herbicides were often used especially in the United States. ${ }^{1,2}$ As important triazine herbicides, atrazine and simazine have been heavily used in maize cultivation and forestry, respectively. They have relatively low absorption in soil and would migrate along the food chains, and their heavy use and presence in the environment have posed a health threat to human beings. Recently, they have been considered as a group to be endocrine-disrupting chemicals. ${ }^{3}$ The European Union Drinking Water Directive sets official regulations on the maximum admissible concentrations in drinking water as $0.1 \mu \mathrm{g} \mathrm{L}^{-1}$ for an individual pesticide and $0.5 \mu \mathrm{g} \mathrm{L}{ }^{-1}$ for total pesticides, ${ }^{4}$ whereas in surface water the alert and alarm threshold values are typically 1 and $3 \mu \mathrm{g} \mathrm{L}^{-1}$. Hence, the development of sensitive analytical methods is very crucial for screening the presence and amounts of pesticides and preventing toxicological risks.

In general, gas chromatography (GC) and high performance liquid chromatography (HPLC) are the techniques popularly used for the determination of atrazine and simazine. ${ }^{6-9}$ Recently, gas chromatography-mass spectrometry (GC-MS), amperometric immunosensor, and adsorptive stripping voltammetric determination were developed for the analysis of atrazine and

† To whom correspondence should be addressed.

E-mail: zhouqx@henannu.edu.cn simazine,${ }^{10-13}$ yet HPLC is still the robust technology for the analysis of such herbicides. However, using a sample pretreatment procedure is necessary for cleanup and preconcentration of target analytes. Some methods have been developed for such goals, for example, supercritical fluid extraction, ${ }^{14}$ solid phase extraction, ${ }^{15}$ and microwave-assisted extraction. ${ }^{16}$ Liquid phase microextraction (LPME) is a novel technique and attracts increasing attention due to its merits, which include simplification, low cost, and high enrichment factor. ${ }^{17,18}$

Recently, Rezaee, Assadi and coworkers have developed a novel liquid extraction named dispersive liquid-liquid microextraction (DLLME) based on a ternary component solvent system such as homogeneous liquid-liquid extraction and cloud point extraction. ${ }^{19}$ The experimental results showed that this microextraction technique exhibited a high performance and powerful enrichment. Thus it has been successfully applied to the analysis of polycyclic aromatic hydrocarbons, ${ }^{19}$ triazine herbicides,$^{20}$ antioxidants, ${ }^{21}$ volatile phenols, ${ }^{22}$ chlorophenols, ${ }^{23}$ chlorobenzenes, ${ }^{24}$ and organophosphorus pesticides, ${ }^{25}$ trihalomethanes, ${ }^{26}$ cadmium,,${ }^{27}$ palladium and cobalt. ${ }^{28}$ However, the enrichment performance of atrazine and simazine was not ideal with carbon tetrachloride and acetone as the extraction solvent and disperser solvent. ${ }^{20}$ In the present work, an improved DLLME method was developed for the rapid and sensitive determination of atrazine and simazine.

\section{Experimental}

Reagents and chemicals

Atrazine and simazine were purchased from the Institute of 
Environmental Prevention and Monitoring of Agriculture Ministry (Beijing, China). HPLC grade acetonitrile and methanol were obtained from Scharlau Chemie SA (Barcelona, Spain). Ultrapure water was prepared in the lab using a water treatment device "Ultra-Clear" (SG Wasseraufbereitungsanlagen, Barsbuttel, Germany). Sodium hydroxide $(0.5 \mathrm{M})$ and hydrochloric acid $(5 \mathrm{M})$ were used for adjusting the $\mathrm{pH}$ value of the water samples.

\section{Apparatus}

A high performance liquid chromatograph system, which consisted of two LC-10ATvp pumps and an SPD-10Avp ultraviolet detector obtained from Shimadzu (Kyoto, Japan), was used for the analysis and separation. A reversed-phase VPODS C18 column $(250 \times 4.6 \mathrm{~mm}$ i.d., particle size $5 \mu \mathrm{m})$ was used for separation at ambient temperature and a Chromato Solution Light Chemstation for LC system was employed to acquire and process chromatographic data. The mobile phase was acetonitrile/water $(62 / 38, \mathrm{v} / \mathrm{v})$ at $0.5 \mathrm{~mL} \mathrm{~min}^{-1}$, and the injection volume and detection wavelength were $20 \mu \mathrm{L}$ and 223 nm, respectively. A Turbo Vap LV evaporator Extraction Station was purchased from Zymark (USA).

\section{DLLME procedure}

In the DLLME procedure, $10 \mathrm{~mL}$ of an aqueous solution containing $10 \mu \mathrm{L} \mathrm{HCl}(0.5 \mathrm{M})$ was placed in a $10 \mathrm{~mL}$ screw cap glass test tube with a conical bottom $(\mathrm{pH} \mathrm{5).} \mathrm{Atrazine} \mathrm{and}$ simazine were spiked at levels of $10 \mu \mathrm{g} \mathrm{L}^{-1}$. One gram of sodium chloride was added in the $10 \mathrm{~mL}$ glass test tube. Then $550 \mu \mathrm{L}$ methanol (disperser solvent) containing $60 \mu \mathrm{L}$ carbon tetrachloride (extraction solvent) was injected into the sample rapidly. After that, a cloudy solution was formed. Then, on centrifuging for $2 \mathrm{~min}$ at $5000 \mathrm{rpm}$, the extraction solvent sunk to the bottom of the conical test tube. The upper aqueous solution was removed, and the residual phase, which was no more than $20 \mu \mathrm{L}$, was blown to near dryness with a mild nitrogen stream in the LV evaporator extraction station. One hundred microliter of acetonitrile was used to dissolve the residue and $20 \mu \mathrm{L}$ of the final solution was injected into the HPLC system for analysis.

\section{Water samples}

In this experiment, three water samples were selected for validating the proposed method. They were tap water, groundwater, and reservoir water. Tap water was collected from our own laboratory after it was allowed to for $10 \mathrm{~min}$ at very large flow rate, and groundwater was obtained from Henan Normal University, Xinxiang city, Henan province. The reservoir water was taken from Shimen reservoir in Xinxiang city, Henan province. Before use, each of the environmental water samples was filtered through a $0.45 \mu \mathrm{m}$ micropore membrane and then stored in a brown glass bottle under low temperature.

\section{Results and Discussion}

\section{The effect of the amount of disperser solvent}

In the DLLME system, disperser solvent is an important component. In the opinion of authors, the target analytes should have relatively low solubility in the disperser solvent and higher solubility in the extraction solvent, and the DLLME could be performed successfully. Atrazine and simazine were relatively weak polar compounds, and they should have higher solubility in acetone than in methanol, because the polarity of methanol is

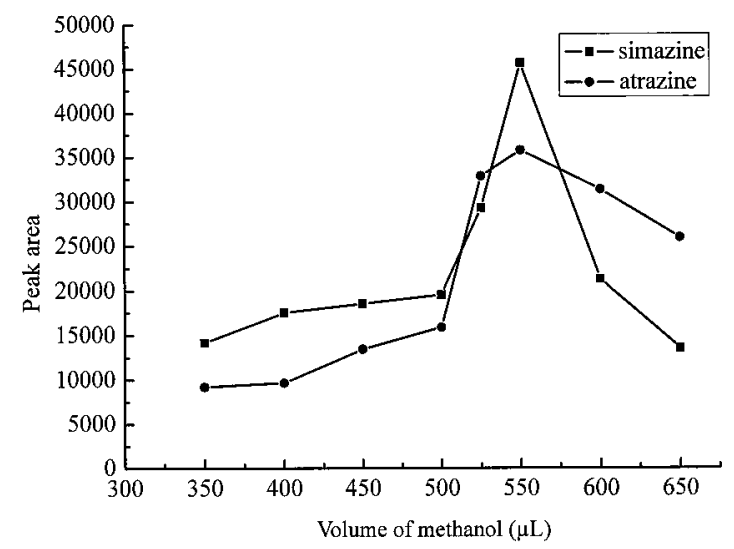

Fig. 1 The effect of the volume of methanol. Conditions: sample, $10 \mathrm{~mL}$; carbon tetrachloride, $34 \mu \mathrm{L} ; \mathrm{pH}, 7$; extraction time, $3 \mathrm{~min}$; centrifuging time, $2 \mathrm{~min}$.

higher than that of acetone. So it is difficult to transfer them into an extraction solvent when acetone is used as disperser solvent. In the preliminary experiments, it was found that methanol was good for use in the DLLME. It was investigated over the range of $350-650 \mu \mathrm{L}$ (Fig. 1), and the extraction factor was very low when the amount of methanol was lower than 500 $\mu \mathrm{L}$, and increased to the best value at $550 \mu \mathrm{L}$ and decreased beyond that volume. From the figure, we found that the trapping performance of atrazine was lower than that of simazine and it was identical with the presumed results.

\section{The effect of sample $\mathrm{pH}$}

Sample $\mathrm{pH}$ was another important parameter in the DLLME procedure. A series of experiments over the $\mathrm{pH}$ range of 3-11 were designed for obtaining the optimal $\mathrm{pH}$ value of sample solution. The results indicated that the best performance occurred at $\mathrm{pH} 5$. Maybe this was because atrazine and simazine were stable in the weakly acidic condition and weakly alkaline environment, while they were easily degraded in strong acidic and alkali conditions. Hence, $\mathrm{pH} 5$ was used in the following experiments.

\section{Select of extraction solvent and its volume}

An extraction solvent should exhibit suitable properties such as low solubility in water and high extraction capability of target analytes. In this experiment, carbon tetrachloride, dichloromethane and trichloromethane were easy to obtain and were selected for investigation for DLLME of atrazine and simazine. The best performance was obtained when carbon tetrachloride was used as the extraction solvent. In order to save organic solvent, a reasonable volume of carbon tetrachloride should be considered. Here, it was optimized over the range of $10-80 \mu \mathrm{L}$ and the experimental data are shown in Fig. 2. The best performance was achieved when $60 \mu \mathrm{L}$ of carbon tetrachloride was utilized in the extraction procedure.

\section{The effect of extraction time and centrifuging time}

In past procedures, it took a certain time interval to complete mass transfer in the microextraction technology. In DLLME procedure, the equilibrium state was reached immediately. The results obtained from the present experiments did not agree with those reported by Nagaraju et al..$^{20}$ The enrichment performance did not decrease with the increase of extraction time, but it had a peak at $5 \mathrm{~min}$ over the range of $0-45 \mathrm{~min}$. Meantime, the optimization of centrifuging time was carried out over the range 


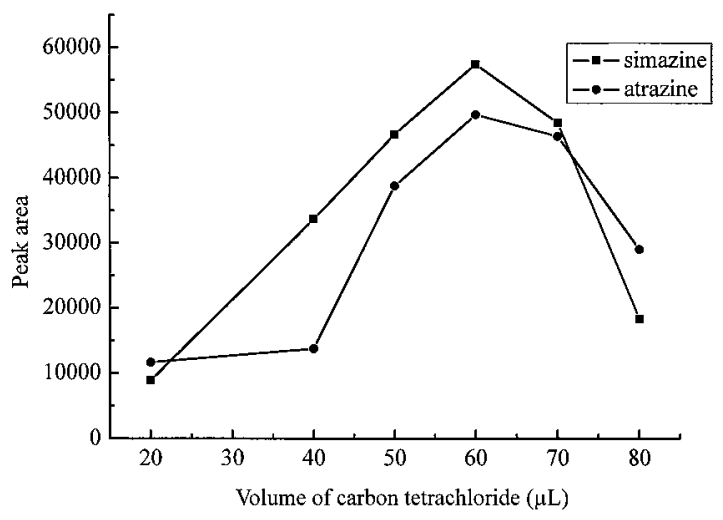

Fig. 2 The effect of the volume of carbon tetrachloride. Conditions: sample, $10 \mathrm{~mL}$; methanol, $550 \mu \mathrm{L} ; \mathrm{pH}, 7$; extraction time, $3 \mathrm{~min}$; centrifuging time, $2 \mathrm{~min}$.

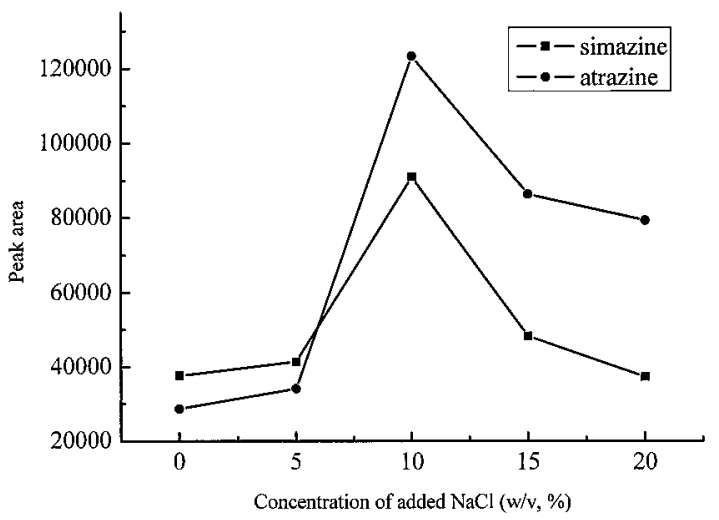

Fig. 3 The effect of salting out. Conditions: sample, $10 \mathrm{~mL}$; carbon tetrachloride, $60 \mu \mathrm{L}$; methanol, $550 \mu \mathrm{L} ; \mathrm{pH}, 5$; extraction time, $5 \mathrm{~min}$; centrifuging time, 2 min.

of $1-7 \mathrm{~min}$. The experimental results showed that the better extraction recoveries were achieved at $2 \mathrm{~min}$.

\section{The effect of salting out}

To add a small amount of sodium chloride into the sample solution would promote the transfer from the aqueous phase to the adsorbent phase or organic solvent phase. So we investigated such addtions in the range of $0-20 \%(\mathrm{w} / \mathrm{v})$, the results are shown in Fig. 3. It was evident that the extraction factor increased with the addition of sodium chloride over the range of $0-10 \%$, and decreased with the further addition. The extraction performance of atrazine increased markedly. Meanwhile, it was found that a small amount of sodium chloride was sedimented after dryness with nitrogen stream when $10 \%$ salt was added, and the quantity of salt that sedimented was higher when the addition of sodium chloride was over $10 \%$. The sedimented salt would adsorb part of the atrazine and simazine, and this led to a decrease of the amounts of atrazine and simazine recovered into the final acetonitrile solution. Hence, $10 \%$ addition of sodium chloride was used for obtaining an extraction factor.

\section{Analytical parameters of proposed method}

Under the optimal conditions obtained above, the analytical performance of the proposed method was investigated. The method detection limits for atrazine and simazine were 0.1 and
Table 1 Analysis of real water samples and recoveries spiked with atrazine and simazine

\begin{tabular}{|c|c|c|c|c|c|c|}
\hline \multirow{3}{*}{ Compound } & \multicolumn{6}{|c|}{ Recovery, \% } \\
\hline & \multicolumn{2}{|c|}{ Tap water } & \multicolumn{2}{|c|}{ Groundwater } & \multicolumn{2}{|c|}{$\begin{array}{c}\text { Reservoir } \\
\text { water }\end{array}$} \\
\hline & Blank & Spiked & Blank & Spiked & Blank & Spiked \\
\hline Atrazine & 一 $^{\mathrm{a}}$ & $84.7^{\mathrm{b}}$ & - & 69.9 & - & 89.8 \\
\hline Simazine & - & 80.2 & - & 60.7 & - & 91.4 \\
\hline
\end{tabular}

a. Not found.

b. Mean value $(n=3)$.
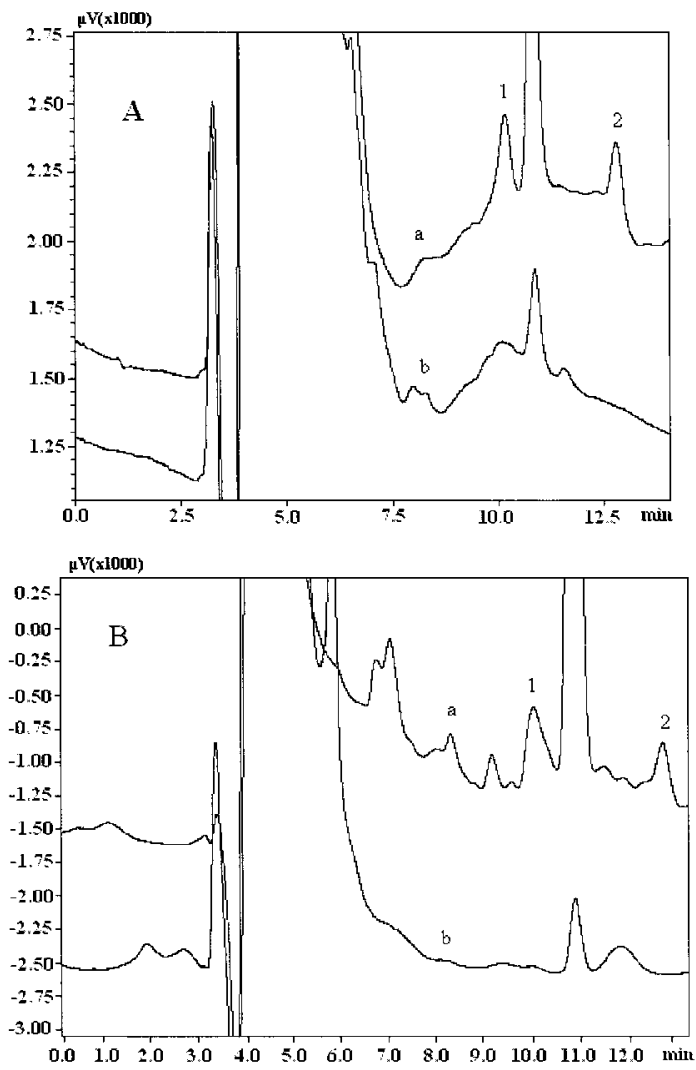

Fig. 4 The chromatograms of real water samples. Conditions: sample, $10 \mathrm{~mL}$; carbon tetrachloride, $60 \mu \mathrm{L}$; methanol, $550 \mu \mathrm{L} ; \mathrm{pH}$ 5; salt addition, $10 \%$; extraction time, $5 \mathrm{~min}$; centrifuging time, 2 min. 1, Atrazine; 2, simazine; a, spiked; b, blank; A, reservoir water sample; B, groundwater sample.

$0.04 \mu \mathrm{g} \mathrm{L}^{-1}(S / N=3)$, respectively. The experimental results also demonstrated that there was excellent linear relationship over the concentration ranges of $0.5-50 \mu \mathrm{g} \mathrm{L}^{-1}$ for atrazine and 0.1 - $50 \mu \mathrm{g} \mathrm{L}^{-1}$ for simazine with favorable correlation coefficients of 0.9991 and 0.9955 , respectively. The precision was obtained as 6.4 and $4.6 \%(\mathrm{RSD}, n=6)$ for atrazine and simazine, respectively.

\section{Analysis of real water samples}

The proposed method was applied to the analysis of three environmental water samples: tap water, groundwater, and reservoir water. The results are listed in Table 1. The typical chromatograms of real water samples are exhibited in Fig. 4. It was found that there was no atrazine and simazine in any water 
sample. In order to validate the applicability of proposed method, we ananlyzed environmental water samples spiked at $1 \mathrm{ng} \mathrm{mL} \mathrm{m}^{-1}$, and satisfactory recoveries in the range of $60.7-91.4 \%$ were achieved for the real water samples used. The results indicated that the established method could be competitive in the monitoring of atrazine and simazine in the environment.

\section{Conclusions}

An alternative method was developed for the sensitive and rapid determination of atrazine and simazine in environmental water samples based on dispersive liquid-liquid microextraction. The experimental results indicated that excellent extraction performance was achieved with carbon tetrachloride as the extraction solvent and methanol as the disperser solvent. The proposed method had merits such as simplificity, rapidity and sensitivity and would be a competitive method in the environmental analysis. For samples containing large amounts of salts, the ionic strength should be investigated in detail using the procedures developed.

\section{Acknowledgements}

This work was supported by the National Hi-Tech Development Plan of 863 (2006AA06Z424), the Personal Innovation Foundation of Universities in Henan Province ([2005]126), the Natural Science Foundation of Henan Province (072300460010), the fund of Henan Normal University (No. 2006PL06), and the funds from the Henan Key Laboratory for environmental pollution control.

\section{References}

1. D. W. Gammon, C. N. Aldous, W. C. Carr Jr., J. R. Sanborn, and K. F. Pfeifer, Pest Manage. Sci., 2005, 61, 331.

2. L. P. Gianessi and M. B. Marcelli, Pesticide Use in U.S. Crop Production: 1997 National Summary Report, National Center for Food and Agricultural Policy, Washington, D.C., 2000.

3. H. Jiang, C. Adams, N. Graziano, A. Roberson, M. McGuire, and D. Khiari, Environ. Sci. Technol., 2006, 40, 3609.

4. EU Directive 80/778/EEC, Commission of the European Union, 1980.

5. EEC Drinking Water Guidelines, 80/779/EEC, EEC No.
L229/11-29, EEC, Brussels, August 30, 1980.

6. S. Usenko, K. J. Hageman, D. W. Schmedding, G. R. Wilson, and S. L. Simonich, Environ. Sci. Technol., 2005, 39, 6006 .

7. C. Stalikas, D. Knopp, and R. E. Niessner, Environ. Sci. Technol., 2002, 36, 3372.

8. T. Koal, A. Asperger, J. Efer, and W. Engewald, Chromatographia, 2003, 57, 93.

9. I. Baranowska, H. Barchanska, and E. Pacak, Environ. Pollut., 2006, 143, 206.

10. N. Maleki, G. Absalan, A. Safavi, and E. Farjami, Anal. Chim. Acta, 2007, 581, 37.

11. K. Grennan, G. Strachan, A. J. Porter, A. J. Killard, and M. R. Smyth, Anal. Chim. Acta, 2003, 500, 287.

12. E. Turiel, P. Fernandez, C. Perez-Conde, A. M. Gutierrez, and C. Camara, Talanta, 1998, 47, 1255.

13. J. J. B. Nevado, C. G. Cabanillas, M. J. V. Llerena, and V. R. Robledo, Microchem. J., 2007, 87, 62.

14. J. W. Pensabene, W. Fiddler, and D. J. Donoghue, J. Agric. Food Chem., 2000, 48, 1668.

15. M. C. Bruzzoniti, C. Sarzanini, G. Costantino, and M. Fungi, Anal. Chim. Acta, 2006, 578, 241.

16. J. Cheng, M. Liu, X. Zhang, L. Ding, Y. Yu, X. Wang, H. Jin, and H. Zhang, Anal. Chim. Acta, 2007, 590, 34.

17. Y. He and H. K. Lee, Anal. Chem., 1997, 69, 4634.

18. Y. Wang, Y. C. Kwok, Y. He, and H. K. Lee, Anal. Chem., 1998, 70, 4610.

19. M. Rezaee, Y. Assadi, M. M. Hosseini, E. Aghaee, F. Ahmadi, and S. Berijani, J. Chromatogr., A, 2006, 1116, 1.

20. D. Nagaraju and S. D. Huang, J. Chromatogr., A, 2007, $1161,89$.

21. M. A. Farajzadeh, M. Bahram, and J. Å Jönsson, Anal. Chim. Acta, 2007, 591, 69.

22. L. Farina, E. Boido, F. Carrau, and E. Dellacassa, J. Chromaogr., A, 2007, 1157, 46.

23. N. Fattahi, Y. Assadi, M. R. M. Hosseini, and E. Z. Jahromi, J. Chromaogr., A, 2007, 1169, 63.

24. R. R. Kozani, Y. Assadi, F. Shemirani, M. R. M. Hosseini, and M. R. Jamali, Talanta, 2007, 72, 387.

25. S. Berijani, Y. Assadi, M. Anbia, M. R. M. Hosseini, and E. Aghaee, J. Chromatogr., A, 2006, 1123, 1.

26. R. R. Kozani, Y. Assadi, F. Shemirani, M. R. M. Hosseini, and M. R. Jamali, Chromatographia, 2007, 66, 81.

27. E. Z. Jahromi, A. Bidari, Y. Assadi, M. R. M. Hosseini, and M. R. Jamali, Anal. Chim. Acta, 2007, 585, 305.

28. N. Shokoufia, F. Shemirani, and Y. Assadi, Anal. Chim. Acta, 2007, 597, 349. 